\title{
Co-Abuse of Opiates and Benzodiazepines
}

\author{
S. Rooney ${ }^{1}$, G. Kelly ${ }^{2}$, L. Bamford ${ }^{1}$, D. Sloan ${ }^{1}$, J. J. O'Connor' ${ }^{1}$. \\ ${ }^{1}$ The National Drug Treatment Centre, Pearse Street, Dublin 2. \\ ${ }^{2}$ Department of Statistics, University College Dublin, Belfield, Dublin 4.
}

\begin{abstract}
The objective of the study was to assess what differences exist between individuals who are dependent on opiates and benzodiazepines and compare to those who are dependent on opiates. A questionnaire was compiled and administered to patients who had been consecutively admitted to an inpatient drug treatment unit. The prevalence of benzodiazepine dependency was 54 per cent [ $n=34]$. Patients dependent on benzodiazepines and opiates were significantly older, had been admitted for methadone stabilisation and were more likely to have been prescribed a methadone maintenance programme prior to admission. They had used heroin longer, benzodiazepines more frequently, at larger doses for a longer duration of time and tended to use more drugs in general. They were found to be more psychologically vulnerable than those not dependent on benzodiazepines as they were significantly more likely to have described a past experience of depression and a past episode of deliberate self harm.
\end{abstract}

\section{Introduction}

Benzodiazepine use by polydrug users is an extensive and serious problem. The prevalence of use has been recorded at 70 per cent in a study of patients on a methadone maintenance programme, whereby the patterns and doses of diazepam used were primarily abusive rather than therapeutic ${ }^{1}$. An estimation of benzodiazepine dependency has been rated as being between 15 per cent and 44 per cent $^{2,3,4}$. Research indicates that benzodiazepine polydrug users are more likely to inject, to share injected equipment and have a higher risk of H.I.V. and hepatitis $\mathrm{C}^{5,6,7,8,9,10}$. Darke et $\mathrm{al}^{8,9}$ found that benzodiazepines-using methadone maintenance clients had higher levels of depression, anxiety, global psychopathology, poorer health and poorer social functioning. Hortog and Tuse ${ }^{11}$ demonstrated that $^{2}$ diazepam-using methadone maintenance clients had more drug and psychiatric problems than diazepam users alone.

The aim of this study was to assess the prevalence and pattern of benzodiazepine dependency in a sample of Irish drug users who take opiates and benzodiazepines and who require inpatient treatment and to identify differences that exist with other drug users who are not dependent on benzodiazepines.

\section{Method}

All patients who were consecutively admitted to an inpatient drug treatment unit over a fourmonth period were included in the study. The inpatient unit consists of 10 beds and admissions are for methadone stabilisation, methadone detoxification and benzodiazepine detoxification programmes. A clinical decision on admission was made, separate from the study, to commence a drug user on a benzodiazepine detoxification programme when their drug history indicated persistent daily use of

\footnotetext{
Author for correspondence:

Dr. Siobhan Rooney,

Senior Registrar,

Our Lady's Hospital,

Navan, Co. Meath.
}

This article is a reproduction of that published in: Irish Journal of Medical Science, 168(1), March 1999, pp. 36-41. Pagination may not match that of the original. 
benzodiazepines and there was a risk of benzodiazepine withdrawals if they were not commenced on a detoxification programme. The benzodiazepine detoxification programme consisted of a reducing course of lorazepam, commencing at $1 \mathrm{mg} 3$ times a day, reducing every 3 days with completion of the detoxification in 9 days. Extra doses of lorazepam were prescribed if required.

A questionnaire was compiled which sought information on demographic details, reasons for admission, past psychiatric/psychological problems, pattern of heroin, benzodiazepine and other drug use, treatment details pertaining to the admission and subsequent discharge details. The questionnaire was administered to patients while an inpatient in the unit. Results from patients who required a benzodiazepine detoxification programme were compared to results from the control group of patients who did not require a benzodiazepine detoxification programme. All results were subjected to appropriate statistical tests of significance including Chi-Square and Fisher's exact test. Statistical significance was set at $\mathrm{p} \leq 0.05$. Predictor variables were identified through Logistic Regression analysis.

\section{Results}

The total sample consisted of 63 admissions, 34 [54 per cent] required a benzodiazepine detoxification programme and the remaining 29 [46 per cent] constituted the control group. There were no significant gender differences between the 2 groups, but more females [ 61.8 per cent $n=21$ ] required a benzodiazepine detoxification programme. The benzodiazepine detoxification group were significantly older than the control group, with a mean age of $26.5 \mathrm{yr}$ compared to $22 \mathrm{yr}, \mathrm{p}=0.004$. There were no significant differences between the groups regarding marital, employment and educational status or in the number of first admission and repeated admission, although a greater proportion of patients in the benzodiazepine detoxification group had more repeated admission compared to the control group (Table I).

TABLE 1

Demographic Characteristics of the Sample

\begin{tabular}{lll}
\hline & Control Group & $\begin{array}{l}\text { Benzodiazepine Detoxification } \\
\text { Group }\end{array}$ \\
\hline Sex & M: $58.6 \%[\mathrm{n}=17]$ & M:3802\% [n=13] \\
& F: $41.4 \%[\mathrm{n}=12]$ & F: $61.8 \%[\mathrm{n}=21]$ \\
Martial Status & Single: $69 \%[\mathrm{n}=20]$ & Single: $67.65 \%[\mathrm{n}=23]$ \\
& Married/Co-habitating: $27.6 \%[\mathrm{n}=8]$ & Married/Co-habitating: $20.6 \%[\mathrm{n}=7]$ \\
& Separated: $3.45 \%[\mathrm{n}=11]$ & Separated: $5.9 \%[\mathrm{n}=2]$ \\
& Widowed: $0 \%$ & Widows: $5.9 \%[\mathrm{n}=2]$ \\
Employment Status & Unemployed: $96.55 \%[\mathrm{n}=28]$ & Unemployed: $94.1 \%[\mathrm{n}=32]$ \\
Educational Status & Primary School: $13.8 \%[\mathrm{n}=4]$ & Primary School: $26.5 \%[\mathrm{n}=9]$ \\
& Secondary School: $86.2 \%[\mathrm{n}=25]$ & Secondary School: $70.6 \%[\mathrm{n}=24]$ \\
School Exams & Higher Education: $0 \%$ & Higher Education: $2.9 \%[\mathrm{n}=1]$ \\
First admission & $34.5 \%[\mathrm{n}=10]$ & $20.6 \%$ [n=7] \\
& $72.4 \%[\mathrm{n}=21]$ & $52.9 \%[\mathrm{n}=18]$ \\
\hline
\end{tabular}

More patients who had a benzodiazepine detoxification programme described having a past psychiatric history or previous psychological problems, 32.35 per cent [ $\mathrm{n}=11]$ compared to 13.8 per cent $[n=4]$ in the control group, $p=0.14$. Of these, significantly more in the benzodiazepine detoxification group [ $\mathrm{n}=10]$ described suffering subjective feelings of depression in the past, in contrast to 2 in the control group, $\mathrm{p}=0.045$. Individuals who had received a benzodiazepine detoxification programme were significantly more likely to have had episodes of deliberate self harm, 29.4 per cent $[n=10]$ compared to 6.9 per cent $[n=10]$ in the control group, $p=0.045$. These episodes were specifically carried out by patients who had described previous episodes of depression, $p=0.001$ (Table II). Few patients from either group described ever having problematic alcohol use. 
Significantly more patients who had received a benzodiazepine detoxification programme had been prescribed methadone as part of a methadone maintenance programme prior to admission, 67.65 per cent [ $n=23$ ] compared to 37.9 per cent [ $n=11]$ in the control group, $p=0.024$ and they tended to received a higher average daily methadone dose of $45 \mathrm{mg}$, in contrast to $34.4 \mathrm{mg}$ for the control group, $\mathrm{p}=0.052$. Significantly more in the benzodiazepine detoxification group had been admitted to the inpatient unit for stabilisation of methadone, 58.8 per cent $[n=20]$ vs 13.8 per cent $[n=4]$ in the control group. whereas significantly more in the control group had been admitted for a methadone detoxification programme, $\mathrm{p}=0.0002$.

The infection status for both groups was compared. Three from the benzodiazepine detoxification group had H.I.V. status positively identified, 1 from the control group and 3 from the benzodiazepine group had hepatitis B. Although more in the benzodiazepine detoxification group had hepatitis C, 70.6 per cent [n=24] compared to 48.3 per cent [n=14], this was not found to be statistically significant. The prevalence of hepatitis $C$ in the sample was 60.3 per cent.

TABLE II

Past psychiatric history/psychological difficulties

\begin{tabular}{lccc}
\hline & $\begin{array}{l}\text { Control } \\
\text { group } \\
\mathbf{n = 4}[\mathbf{6 . 3 \%} \\
{[\mathbf{1 3 . 8 \%}]}\end{array}$ & $\begin{array}{l}\text { Benzodiazepine } \\
\text { detoxification group } \\
\mathbf{n = 1 1}[\mathbf{1 7 . 5 \% ]} \\
\mathbf{[ 3 2 . 3 5 \% ]}\end{array}$ & $\begin{array}{l}\text { Percent of the total } \\
\text { sample } \\
\mathbf{n}=\mathbf{1 5}[\mathbf{2 3 . 8 \%}]\end{array}$ \\
\hline Per cent of each group & $2[6.9 \%]$ & $* 10[29.4 \%]$ & $12[19 \%]$ \\
Depression & $0 \%$ & $1[2.9]$ & $1[1.6 \%]$ \\
Schizophrenia & $2[6.9 \%]$ & $0 \%$ & $2[3.2 \%]$ \\
Learning difficulties & $0 \%$ & $1[2.9 \%]$ & $1[1.6 \%]$ \\
Alcohol use & $2[6.9 \%]$ & $* 10[29.4 \%]$ & $12[19 \%]$ \\
Deliberate self harm & & & \\
\hline
\end{tabular}

$*_{p}=<0.05$

\section{Pattern of heroin use}

The mean age of the control group to commence taking any drug was $15.8 \mathrm{yr}$, and $15.5 \mathrm{yr}$ for the benzodiazepine detoxification group. Patients in the benzodiazepine detoxification group were using heroin significantly longer than the control group i.e. $6.8 \mathrm{yr}$ compared to $3.2 \mathrm{yr}, \mathrm{p}=0.005$. The most common frequency of use was daily with 100 per cent [ $n=22]$ of the control group and $85.2 \%$ $[\mathrm{n}=23]$ of the benzodiazepine detoxification group taking heroin daily. There was no significant difference in the average number of grams of heroin taken by each group, 1 gram for the control group and 1.2 grams for the benzodiazepine detoxification group. The route of administration of heroin was comparable in both groups although more in the benzodiazepine detoxification group injected (Figure 1).

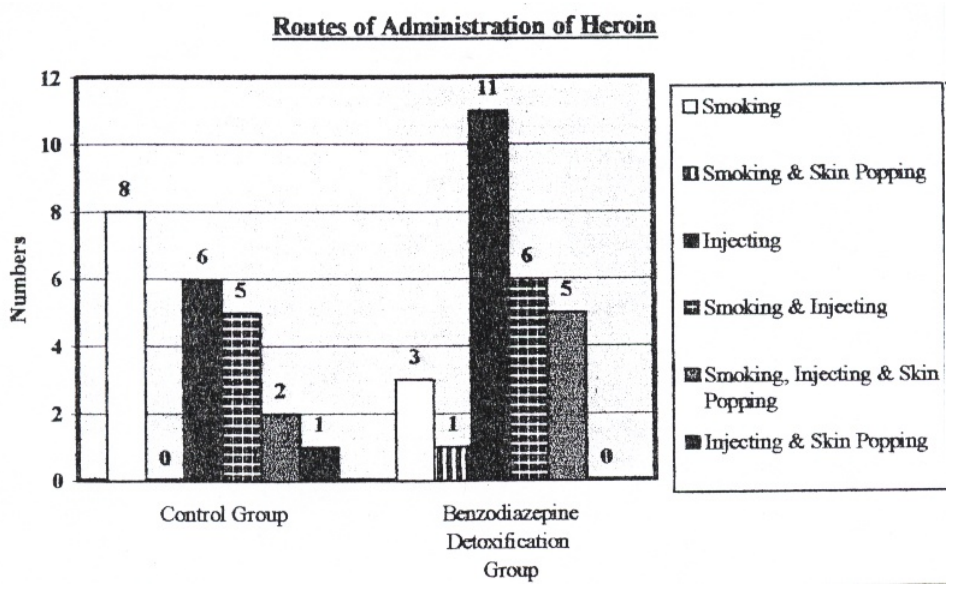

Fig. 1 - Routes of Administration of Heroin 


\section{Other substance use}

A greater percentage in the benzodiazepine detoxification group used cannabis, cocaine, amphetamines and particularly antidepressants $[\mathrm{p}=0.052]$ and to have taken these drugs over a longer period of time (Table III). The frequency of use of all these drugs was comparable between the 2 groups except for antidepressants which were taken significantly more frequently by the benzodiazepine detoxification group, $\mathrm{p}=0.012$.

\section{Benzodiazepine use}

The average age for commencing benzodiazepine use was similar in both groups, $15.3 \mathrm{yr}$ and $16.8 \mathrm{yr}$ for the control group and benzodiazepine detoxification group respectively. As one would expect because of the nature of the study, patients who had a benzodiazepine detoxification programme significantly used more benzodiazepines than the control group, $\mathrm{p}=0.007$. However, a large amount of patients in the control group, 79.3 per cent [n=23], had taken benzodiazepines at some stage, but their use was not daily and was at lower doses than for the benzodiazepine detoxification group.

The most popular benzodiazepines used by both groups were flunitrazepam, diazepam and flurazepam (Table IV). Flunitrazepam, diazepam and flurazepam were used at higher doses, more frequently and generally for a longer duration of time by patients in the benzodiazepine detoxification group. Frequency was on a daily or 2 to 6 times a week basis as opposed to patients in the control group who tended not to have used these benzodiazepines within the last month. The average daily doses of the 3 most popular benzodiazepines used were $115.5 \mathrm{mg}$ for diazepam, $8.5 \mathrm{mg}$ for flunitrazepam and $233.6 \mathrm{mg}$ for flurazepam (Table IV).

TABLE III

A Comparison to Other Drug Use

\begin{tabular}{|c|c|c|c|c|c|}
\hline & Cannabis & Cocaine & Amphetamines & Ecstasy & Antidepressants \\
\hline Control group & $\mathrm{n}=17[58.6 \%]$ & $\mathrm{n}=4[13.8 \%]$ & $\mathrm{n}=3[10.3 \%]$ & $\mathrm{n}=9[31 \%]$ & $\mathrm{n}=2[6.9 \%]$ \\
\hline $\begin{array}{l}\text { Benzodiazepine } \\
\text { detoxification group }\end{array}$ & $\mathrm{n}=25[73.5 \%]$ & $* n=12[35.3 \%]$ & $\mathrm{n}=6[17.7 \%]$ & $\mathrm{n}=9[26.5 \%]$ & $* * * \mathrm{n}=9[26.5 \%]$ \\
\hline Duration of use & & & & & \\
\hline Control group & $8.6 \mathrm{yrs}$ & $2.8 \mathrm{yrs}$ & $4.3 \mathrm{yrs}$ & $2 \mathrm{yrs}$ & $1.5 \mathrm{yrs}$ \\
\hline $\begin{array}{l}\text { Benzodiazepine } \\
\text { detoxification group } \\
\text { Frequency of daily } \\
\text { use }\end{array}$ & $11.3 \mathrm{yrs}$ & 4 yrs & $7.4 \mathrm{yrs}$ & $* * 4.4$ yrs & $2.7 \mathrm{yrs}$ \\
\hline Control group & $\mathrm{n}=8[47.1 \%]$ & $\mathrm{n}=1$ & 0 & & 0 \\
\hline $\begin{array}{l}\text { Benzodiazepine } \\
\text { detoxification group }\end{array}$ & $\mathrm{n}=9[36 \%]$ & $\mathrm{n}=2$ & 0 & & $* * * * \mathrm{n}=5$ \\
\hline
\end{tabular}

$* \mathrm{p}=0.08 \quad * * \mathrm{p}=0.07 * * * \mathrm{p}=0.0052 \quad * * * * \mathrm{p}=0.012$ 
TABLE IV

The Most Popular Benzodiazepine Used

\begin{tabular}{llll}
\hline & \multicolumn{1}{c}{$\begin{array}{c}\text { Control } \\
\text { group }\end{array}$} & \multicolumn{1}{c}{$\begin{array}{c}\text { Benzodiazepine } \\
\text { detoxification } \\
\text { group }\end{array}$} \\
\hline Rohypnol & $* \% / \mathrm{n}$ & $44.8 \%[\mathrm{n}=13]$ & $91.2 \%[\mathrm{n}=31]$ \\
& $*$ Daily use [\%/n] & $7.7 \%[\mathrm{n}=1]$ & $48.4 \%[\mathrm{n}=15]$ \\
& *Duration [yrs] & 2.8 & 4.4 \\
& *Average dose [mg] & 1.25 & 8.5 \\
Valium & $* \% / \mathrm{n}$ & $65.5 \%[\mathrm{n}=19]$ & $88.2 \%[\mathrm{n}=30]$ \\
& $*$ Daily use [\%/n] & $5.3 \%[\mathrm{n}=1]$ & $60 \%[\mathrm{n}=18]$ \\
& $*$ Duration [yrs] & 3.9 & 7.3 \\
& *Average dose [mg] & 8.9 & 115.5 \\
& $\% / \mathrm{n}$ & $51.7 \%[\mathrm{n}=15]$ & $70.6 \%[\mathrm{n}=24]$ \\
& $*$ Daily use [\%/n] & $13.3 \%[\mathrm{n}=2]$ & $62.5 \%[\mathrm{n}=15]$ \\
& $*$ Duration [yrs] & 3.3 & 7 \\
& $*$ Average dose [mg] & 38.7 & 233.6 \\
\hline
\end{tabular}

$* \mathrm{p} \leq 0.05$

Other benzodiazepines that were used by the benzodiazepine detoxification group included, alprazolam [ $\mathrm{n}=3]$, chlormethiazole $[\mathrm{n}=1]$ and zopiclone $[\mathrm{n}=1]$. Zopiclone had also been used by a patient in the control group as too was temazepam [n=2], lorazepam [n=1] and chlordiazepoxide $[\mathrm{n}=1]$.

There were no significant differences in the mode that benzodiazepines were used between the 2 groups, with 16 [69.6 per cent] in the control group and 22 [64 per cent] in the benzodiazepine detoxification group taking benzodiazepines orally.

\section{Treatment details}

As expected there were significantly more patients in the benzodiazepine detoxification group who had benzodiazepines in their urine, 97.1 per cent [ $n=33$ ] compared to 24.1 per cent $[n=7]$ in the control group, $\mathrm{p}=0.00$. Of the 7 in the control group whose urines were positive for benzodiazepines only 1 had used benzodiazepines daily. They had similar preferences for specific benzodiazepines as the benzodiazepine detoxification group but their average dose of use was much lower, with an average dose for diazepam of $8.9 \mathrm{mg}, 1.25 \mathrm{mg}$ for flunitrazepam and $38.7 \mathrm{mg}$ for flurazepam when taken (Table IV).

Of those in the benzodiazepine detoxification group, 82.3 per cent [ $\mathrm{n}=28$ ] subjectively experienced benzodiazepine withdrawals. Withdrawals were most commonly reported as occurring within the first $48 \mathrm{hr}$ of admission, 64.3 per cent [ $\mathrm{n}=18$ ], 21.4 per cent [n=6] experienced withdrawals between 48 and $72 \mathrm{hr}$ and 10.7 per cent [n=3) experienced them after $48 \mathrm{hr}$. Lorazepam was prescribed in 31 cases [91.2 per cent] or combined with diazepam in another 2 cases, accounting for 33 treatment episodes. The average maximum dose of lorazepam used was $2.9 \mathrm{mg}$, range between 1 and $6 \mathrm{mg}$ and $15 \mathrm{mg}$ for diazepam. The final case was treated with chlordiazepoxide because of an associated history of alcohol dependency, at a maximum dose of $60 \mathrm{mg}$. The mean duration of a benzodiazepine detoxification programme was 8.4 days and the programme was completed in 30 of the 34 treatment episodes. The remainder had taken their own discharge against medical advice prior to completion of the programme.

Discharge status indicated that significantly more form the benzodiazepine detoxification group were discharged back to the National Drug Treatment Unit [55.9 per cent, $n=19, p=0.001$ ] and more from the control group were discharged to the general practitioner [ 37.9 per cent, $n=11$ ] vs 0 per 
cent in the benzodiazepine detoxification group] or to the rehabilitative services [ 34.5 per cent, $n=10$ ] (Figure 2).

\section{Discharge Status}

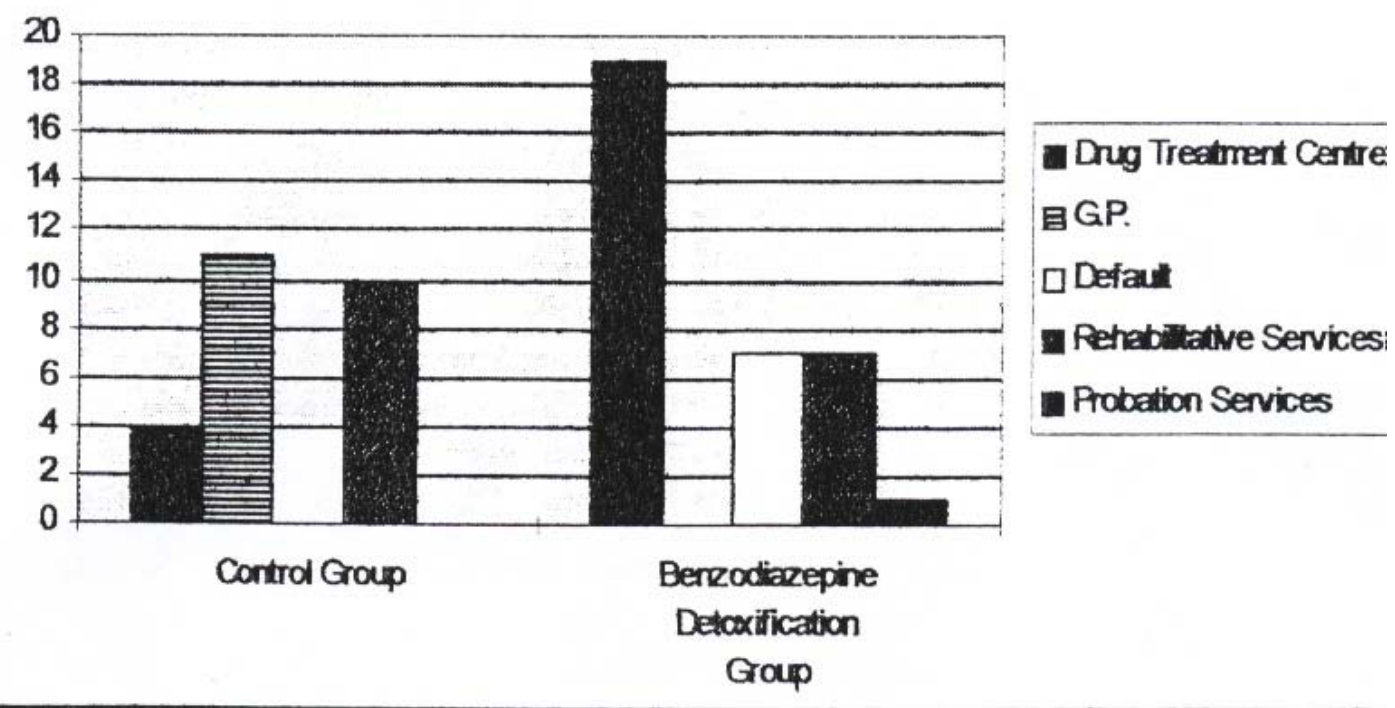

\section{Discussion}

In view of the small sample size, the results in this study may not be representative of all Irish drug users. However the prevalence of benzodiazepine dependency was found to be 54 per cent. This is higher than the quoted prevalence rate of 15-44 per cent in other studies ${ }^{2,3,4}$.

Predictor variables identified for those who require a benzodiazepine detoxification programme included, age, reasons for admission and discharge status. This group was significantly older, the majority had been admitted for a methadone stabilisation programme and were primarily discharged back to the referring drug treatment centre for continued treatment and supervision of urines. Although more women required a benzodiazepine detoxification programme, this was not found to be significant and would not be representative of the general drug using population.

Both groups stated taking drugs and benzodiazepines at similar ages, however those dependent on benzodiazepines had used heroin and other drugs for a longer period of time with benzodiazepine being taken daily and at higher doses. This group also tended to take more drugs in general, particularly cocaine and antidepressants, with antidepressants being taken significantly more frequently. The more frequent use of antidepressants may have been a means of treating the withdrawals from cocaine.

Despite there being 2 groups compared in the study, it is evident that the control group were not adverse to taking benzodiazepines, with only 20.7 per cent [n=6] having never taken benzodiazepines. Patients who had used benzodiazepines in the control group did so less frequently and at lower doses than those in the benzodiazepine detoxification group. This difference may only be because of the shorter duration of drug use by the control group and benzodiazepine dependency may still develop in this group over time in conjunction with continued opiate and other drug use.

In other studies the popularity of particular benzodiazepines that are used has varied. Williams et al. found that diazepam and temazepam were most popular ${ }^{12}$, Gantry et al. identified nitrazepam, chlordiazepoxide and temazepam ${ }^{13}$ and Iguchi et al. rated diazepam, lorazepam and alprazolam as the most preferred benzodiazepines used ${ }^{14}$. Great concerns have also been expressed towards the injection of temazepam ${ }^{5,15,16}$. In this study the use of temazepam is low, with only 2 in the control group having used it and no person in the benzodiazepine detoxification group using it. The most popular benzodiazepines used in this study were flunitrazepam, diazepam and fluazepam. The average dose of diazepam used is higher than in other studies ${ }^{1,12,17}$. Zopiclone is emerging as a new 
drug of use with 2 people in the sample using it despite studies indicating that the drug users have "no liking" for the drug and therefore it has less potential for misuse ${ }^{18}$. This emerging trend of zopiclone being a drug of misuse has previously been documented ${ }^{19}$.

A subjective awareness of benzodiazepine withdrawal symptoms in the majority of cases (64.3 per cent) was within the first $48 \mathrm{~h}$, a similar rate as in the study by Williams et al. ${ }^{12}$. The early onset of symptoms was most likely as a result of a reduction in the amount of benzodiazepines that had been taken daily. The average duration of benzodiazepine detoxification was 8.4 days which, although it is shorter than in other studies ${ }^{12}$, treatment and supervision of urines was continued in the National Drug Treatment Centre on discharge, in 55.9 per cent [ $n=19]$ of cases. Significantly more in the control group were discharged to G.P.s or to the rehabilitative services reflecting a greater potential to complete medical treatment for drug dependency, a movement towards exploring the psychological aspects of drug dependency and a drug-free life. This is not the picture with benzodiazepine dependency as these patients had previously been on methadone maintenance programmes, had been admitted for methadone stabilisation and were being discharged back to their treatment centre to continue a methadone maintenance programme and with that the opportunity for continued stabilisation of drug-use and thus life style.

A result of concern in this study, is that benzodiazepine dependency was associated with greater psychological vulnerability. This group experienced a higher rate of subjective feelings of depression and episodes of deliberate self harm than the control group, confirming previous studies $^{8,9,11}$. This may also explain why a greater percentage use antidepressants and use them more frequently. However despite a higher subjective reporting of psychological distress, none of the clients were regularly attending or obtaining treatment from a psychiatric service.

Although there were 2 groups of drug users compared in this study, the results indicate that these groups are not distinct, but represent differing parts of the spectrum of severity of drug-use. The main differentiating factor between the 2 groups was the longer duration and greater severity (frequency and amount) of drug use by clients who were also dependent on benzodiazepines and with that came difference of treatment programmes. The longer the duration of drug use, the greater the risk of an inevitable progressive deterioration in drug dependency and deterioration of psychological health.

It is therefore paramount that doctors ensure a strict control in prescribing benzodiazepines. The risk of benzodiazepines dependency in polydrug users can be reduced by decreasing the supply of availability of benzodiazepine through educating doctors on the dangers of long-term and indiscriminate prescribing of benzodiazepines. It is important that doctors do not legitimate benzodiazepine use by continuing to prescribe them to drug users. Drug treatment programmes need to focus on and re-evaluate the present treatments for benzodiazepine dependency as continued benzodiazepine use leads to destabilisation of methadone maintenance programmes. Resources need to be concentrated towards the younger drug user to promote drug treatment programmes that focus on and support the young drug-user in achieving a drug-free life.

Benzodiazepine dependency in this study has been associated with greater drug use and greater psychological morbidity. Reducing its prevalence will improve psychological and medical stability for drug users in treatment programmes and protect younger drug users from developing benzodiazepine dependency.

\section{References}

1. Stitzer, M. L. Griffiths, R. R., McLellan, A. T., Grabowski, J., Hawthorne, J. W. Diazepam use among methadone maintenance patients: patterns and dosages. Drug and Alcohol Dependence 1981; 8: 189-199.

2. Higgit, A. C., Leader, M. H., Fonagy, P. Clinical management of benzodiazepine dependence. British Med. J. 1985; 291: 688-690.

3. Tyrer, P., Owen, R., Dawling, S. Gradual withdrawal of diazepam after long-term therapy. Lancet 1983; i: 1402-1406

4. Hallstrom, C., Lader, M. The incidence of benzodiazepine dependency in long-term users. Journal of Treatment and Evaluation 982; 4: 283 
5. Klee, H., Faugier, J., Haues, C., Bouleon, T., Morris, J. Aids-related risk behaviour, polydrug use and temazepam. British Journal of Addiction 1990; 85: 1125-1132.

6. Metzger, D., Woody, G., DePhilipis, D., McLellan, A. T., O’Brien, C. P., Platt, J. J. Risk factors for needle sharing among methadone treated patients. American Journal of Psychiatry 1991; 48: 636-640

7. Darke, S., Hall, W., Ross, M. W., Wodak, A. Benzodiazepine use and H.I.V. risk-taking behaviour among injecting drug users. Drug and Alcohol Dependence 1992; 31: 31-36.

8. Darke, S., Swift, W., Hall, W., Ross, M. Drug use H.I.V. risk-taking and psychosocial correlates of benzodiazepine use among methadone maintenance patients. Drug and Alcohol Dependence 1993; 34: 67-70.

9. Darke, S. Benzo diazepine use among injecting drug users: problems and implications. Addiction 1994; 89: 379-382.

10. Van Den Hoek, J.A.R., Van Haarstrecht, H.J.A., Goudsmit, J., De Wolf, F., Coutinho, R. A. Prevalence, incidence and risk factors of hepatitis $\mathrm{C}$ virus infection among drug users in Amsterdam. Journal of Infectious Diseases 1990; 162: 823-836.

11. Hartog, J., Tusel, D. J. Valium use and abuse by methadone maintenance patients. International Journal of Addictions 1987; 22 (11): 1147-1154.

12. Williams, H., Oyefeso, A., Ghodse, A. H. Benzodiazepine misuse and dependence among opiate addicts in treatment. Irish Journal of Psychological Medicine 1996; 13 (2): 62-64.

13. Garotte, D. J., Wolf, K., Hay, A. W., Raistrick, D. Benzodiazepine Misuse by drug addicts. Annals of Clinical Biochemistry 1997; 34 (1): 68-73.

14. Igushi, M. Y., Handelsman, L., Bickel, W. K., Griffiths, R. R. Benzodiazepine and sedative use/abuse by methadone maintenance clients. Drug and Alcohol Dependence 1993; 32 (3) 257-266.

15. Ruben, S. M., Morrison, C. L. Temazepam in a group of injecting drug users. British Journal of Addiction 1992; 87: 1387-1392.

16. Sakol, M. S., Stark, C., Sykes, R. Buprenorphine and temazepam abuse by drug takers in Glasgow - an increase. British Journal of Addiction 1984; 84: 439-441.

17. Busto, U., Sellers, E. M., Naranjo, C. A., Cappell, H. D., Sanchez-Craig, M., Simkins, J. Patterns of benzodiazepine abuse and dependence. British Journal of Addiction 1986; 81: 8794.

18. Rhone-Poulenc Roher. Zopiclone Monograph. 1994 Adis International Limited.

19. Rooney, S., O’Connor, J. J. Zopiclone, a current drug of misuse (Letter). Addictions 1998; 93 (6): 925 . 